\title{
"Double Evaluation"-the prerequisite and foundation of the municipal-level land and space master plan
}

\author{
Xiangyanan, gaohuanggen, xiataiyun, wanglimeng, lizongyi, wangju, liaojingqian, luojingru \\ (Sichuan Academy of Land and Space Planning, 610081)
}

\begin{abstract}
Resources and environment carrying capacity and space development land suitability assessment (after referred to as "double evaluation") is to recognize the location of natural resources and land space development short board, Highlight the important prerequisites and foundations for the governance and problem orientation of land and space planning in the new era, Played an important role in co-ordinate the three types of layout space to find out the natural resources ${ }^{[1-3]}$, to identify the type of risk, determine the bearing cap and scientific delineation of three control lines, At the same time, it also provides an important starting point for the implementation of monitoring, evaluation and early warning of land and space planning. In order to better support the preparation of land and space planning in the new era, it is necessary to reexamine and re-understand the "double evaluation" work of municipal land and space planning. This article starts with the "Guidelines for the Compilation of Municipal-level Territorial and Spatial Master Plan (Trial)" (hereinafter referred to as "Guide") for the work requirements of "double evaluation", through combing and summarizing the existing problems and important difficulties in actual work, from logical transformation and technical mining The "double evaluation" work is summarized and explored from a dual perspective, in order to provide a reference for the preparation of the municipal-level land and space master plan.
\end{abstract}

\section{Important and difficult points in the practice of "double evaluation"}

\subsection{Pre-action - First draw the board and then drop the pieces}

"Double evaluation", as a pre-research on the basic work of the municipal master plan ${ }^{[4]}$, must not be out of touch with the planning plan. Its role should serve the whole process of planning preparation, in order to optimize the land space protection pattern and delimit three areas and three lines ${ }^{[5-6]}$. Provide important support and reference basis for regions, construction of natural protected area systems and major engineering strategies.

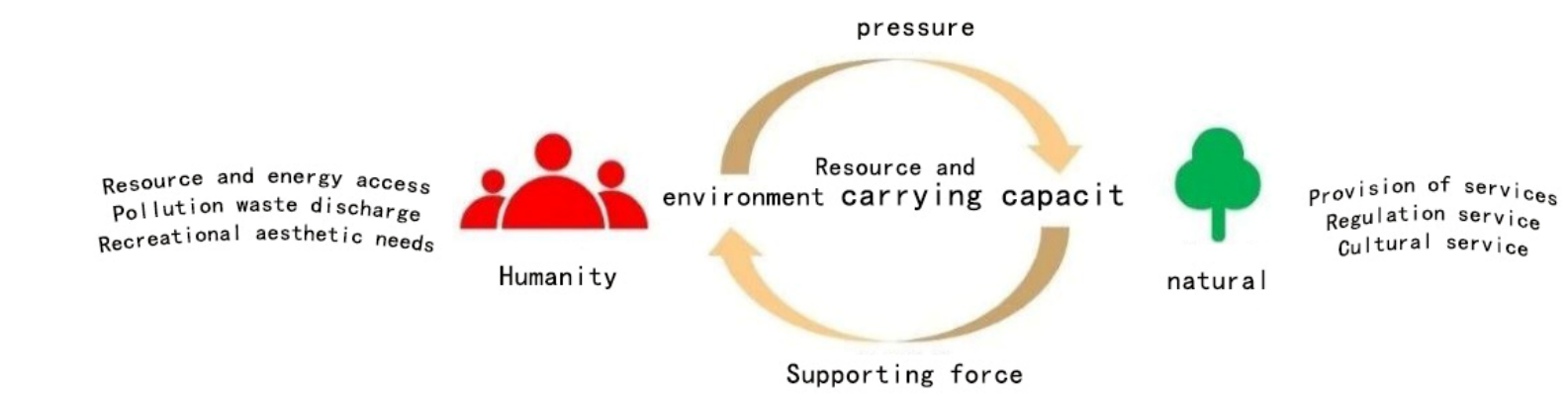

\subsection{Evaluation process-prescribed actions and optional actions}

The current "Technical Guidelines for Evaluation of Resource and Environmental Carrying Capacity and Suitability of Land and Space Development" is a national general evaluation technical guideline of the Ministry of
Natural Resources, and only recommends technical methods for the evaluation of main elements ${ }^{[7-10]}$. The selection of specific evaluation factors and classification thresholds needs to be further optimized and adjusted according to local conditions. Otherwise, it will not be able to reflect the local natural resource endowment, ecological environment capacity and other spatial background characteristics and strongly support the municipal and county-level territorial spatial planning. 
Table 2 Schematic diagram of evaluation elements and evaluation process in double evaluation

\begin{tabular}{|c|c|c|}
\hline Natural elements & Single element evaluation & Integrated evaluation \\
\hline \multirow{3}{*}{$\begin{array}{l}\text { land } \\
\text { resource }\end{array}$} & $\begin{array}{l}\text { The importance of ecological } \\
\text { service functions }\end{array}$ & \multirow{2}{*}{$\begin{array}{l}\text { The importance of } \\
\text { ecological protection }\end{array}$} \\
\hline & Ecological sensitivity & \\
\hline & $\begin{array}{l}\text { Agricultural water supply } \\
\text { conditions }\end{array}$ & \\
\hline \multirow[t]{2}{*}{$\begin{array}{l}\text { Water } \\
\text { resources }\end{array}$} & $\begin{array}{l}\text { Urban water supply } \\
\text { conditions }\end{array}$ & \multirow{2}{*}{$\begin{array}{l}\text { Agricultural } \\
\text { production carrying } \\
\text { scale }\end{array}$} \\
\hline & $\begin{array}{c}\text { Environmental conditions } \\
\text { for agricultural production }\end{array}$ & \\
\hline \multirow{2}{*}{$\begin{array}{c}\text { Soil } \\
\text { resources }\end{array}$} & $\begin{array}{l}\text { Environmental conditions } \\
\text { for urban construction }\end{array}$ & \multirow{2}{*}{$\begin{array}{l}\text { Agricultural } \\
\text { production } \\
\text { suitability }\end{array}$} \\
\hline & $\begin{array}{l}\text { Agricultural farming } \\
\text { conditions }\end{array}$ & \\
\hline \multirow{2}{*}{$\begin{array}{l}\text { Terrestrial } \\
\text { ecology }\end{array}$} & $\begin{array}{l}\text { Urban construction } \\
\text { conditions }\end{array}$ & \multirow[b]{2}{*}{$\begin{array}{l}\text { Urban construction } \\
\text { carrying scale }\end{array}$} \\
\hline & $\begin{array}{c}\text { Meteorological disaster } \\
\text { risk }\end{array}$ & \\
\hline \multirow{3}{*}{$\begin{array}{l}\text { Terrestrial } \\
\text { disaster }\end{array}$} & Disaster risk & 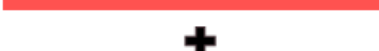 \\
\hline & $\begin{array}{l}\text { Climatic conditions for } \\
\text { agricultural production }\end{array}$ & \multirow{2}{*}{$\begin{array}{c}\text { Suitability of town } \\
\text { construction }\end{array}$} \\
\hline & $\begin{array}{l}\text { Climatic conditions for } \\
\text { urban construction }\end{array}$ & \\
\hline
\end{tabular}

Table 3 Schematic diagram of the basic framework system of dual evaluation

\begin{tabular}{|c|c|c|c|}
\hline 1 review & 2 outputs & 3 points & 4functions \\
\hline \multirow{4}{*}{$\begin{array}{l}\text { "Double } \\
\text { evaluation" }\end{array}$} & \multirow{2}{*}{$\begin{array}{l}\text { Suitability of land } \\
\text { and space } \\
\text { development }\end{array}$} & $\begin{array}{c}\text { Ecological protection } \\
\text { orientation }\end{array}$ & $\begin{array}{c}\text { Analysis of resource and } \\
\text { environmental } \\
\text { endowment }\end{array}$ \\
\hline & & $\begin{array}{c}\text { Agjrisulfural production } \\
\text { orientation }\end{array}$ & $\begin{array}{l}\text { Problem and risk } \\
\text { analysis }\end{array}$ \\
\hline & \multirow{2}{*}{$\begin{array}{l}\text { Resource and } \\
\text { environment } \\
\text { carrying capacity }\end{array}$} & \multirow{2}{*}{$\begin{array}{l}\text { Town development } \\
\text { direction }\end{array}$} & Potential analysis \\
\hline & & & Scenario analysis \\
\hline
\end{tabular}

\subsection{Application of Achievements-Linking Up and Down and Upper and lower conduction}

The city-level "double evaluation" has an obvious linking effect, and is a necessary prerequisite for policy transmission in the spatial planning system ${ }^{[11-12]}$. Therefore, how to combine the city-level "double evaluation" with the characteristics of the city-level resources and environment, and on the basis of undertaking the "double-evaluation" work at the provincial (autonomous region) level, to better support the compilation of municipal and county-level territorial and spatial planning is another important and difficult point of evaluation.

\section{Logic transformation of "double evaluation" under "Guide"}

\subsection{From technology-oriented to management- oriented}

By comparing the multiple editions of guidelines published by the Ministry of Natural Resources, such as the first draft, discussion draft, and solicitation draft, the "double evaluation" has been calculated from hundreds of indicators and multiple models to clarify the directionality of restrictive indicators. Clearly simplify the evaluation process, emphasize the bottom line of control, conform to local reality, and emphasize practicality and operability. 


\subsection{From unified template to local conditions}

Municipal "double evaluation" on the one hand should implement the provincial convergence "double evaluation" control the content, on the other hand the actual situation of the city and county (district), on the basis of the evaluation results on the provincial level, and to add features index factor such as the development of provincial and municipal levels of national strategic requirements, conditions appraisal of agricultural mechanization and infrastructure homogenization judgment indicators can give weight to participate in postscenario analysis, environmental resource endowment judged for regional characteristics, problems and risks, identify future aspects of land development and utilization of the potential of space, to provide support for the subsequent planning application.

\subsection{From total control to space constraints}

Compared with the provincial "dual evaluation", the municipal "dual evaluation" has weaker relativity of evaluation scale, evaluation unit and constraint index. Therefore, the evaluation result does not ask for absolute value, only evaluates relative strength, not calculates carrying capacity. It is to evaluate the carrying capacity; it is not to calculate the suitable scale, but to evaluate the degree of suitability.

\subsection{From absolute judgment to dynamic evaluation}

"Double evaluation" is based on a specific development stage, economic and technological level, production and lifestyle, and ecological protection goals, and within a certain geographical range, resources and environmental elements can support the largest reasonable scale of human activities such as agricultural production and urban construction. Therefore, the double evaluation results are not static. During the implementation period of the plan, it will be affected by changes in conditions such as technological development and the use of resource elements. Therefore, the "dual evaluation" work should be a dynamic evaluation process, requiring new inspections and evaluations within a certain period of time.

\section{3 "Double Evaluation" Technology Mining under "Guide"}

\subsection{Determine the direction of development}

The suitability of land and space development is the core of the "soft guidelines" for land and space planning. Combining geographic location and overall characteristics, through importance and suitability evaluations, different development, protection and utilization methods such as ecological protection, agricultural production, and urban construction are determined. Appropriate level, put forward development strategies, focusing on functional orientation. The carrying capacity of resources and environment as a "hard constraint" is the comprehensive carrying level of natural resources, environmental capacity and ecological service functions in a certain land space for human activities. The focus of the work is to frame rigid boundaries, study and judge constraints on water resources and land resources, and measure agricultural production. And the largest scale of urban construction, focusing on bottom-line control and risk identification. Therefore, the "double evaluation" provides technical support for solving the problem of where the space develops.

\subsection{Optimize development area}

In actual work, in order to highlight the principle of ecological priority, the most important areas of ecological protection have been deducted for suitability evaluation. In addition to the clear functional orientation, there are also areas where multiple functions overlap in suitable spaces and unsuitable areas. Value judgments should be made for this type of space. The ecologically fragile areas and regional facilities (corridors) involved in the "multisuitable space" require Conservation and restoration are incorporated into the ecological space. The overlapping functions of agricultural production and urban construction need to be comprehensively considered in conjunction with the attributes of the surrounding plots to ensure a high degree of land contiguousness and achieve the purpose of space saving and intensive space. For "unsuitable spaces", it is necessary to prioritize the inclusion of agricultural spaces after restoration and rectification, and three types of spaces are delineated.

Table 4 Double evaluation zone

\begin{tabular}{|c|c|}
\hline Very important area for ecological protection \\
\hline $\begin{array}{c}\text { Suitable area for } \\
\text { agricultural production }\end{array}$ & $\begin{array}{c}\text { Unsuitable areas for } \\
\text { agricultural production }\end{array}$ \\
\cline { 1 - 1 } Double suitable area & $\begin{array}{c}\text { Unsuitable area for } \\
\text { urban construction }\end{array}$ \\
\cline { 1 - 2 } $\begin{array}{c}\text { Suitable area for town } \\
\text { construction }\end{array}$ & Double inappropriate zone \\
\hline Doun
\end{tabular}

It then guides the delineation of the spatial pattern and guidance control line, and comprehensively analyzes and evaluates the actual construction, utilization, and protection of various spaces into the analysis framework to identify current problems and risks, and predict the scale and spatial layout of agriculture and urban potential. With reference to the suitability of various types, guide the optimization of the spatial development pattern and structure of the land, delineate or optimize urban development boundaries, permanent basic farmland, and ecological protection red lines. Carrying capacity evaluations in different directions can also provide a basis for the formulation of planning goals and indicators, and determine the limit capacity of urban ecology, agriculture, and urban space, as forest coverage, forest retention, 
permanent basic farmland protection rate, and cultivated land The basis for setting indicators such as inventory and development intensity. Finally, the bottom line thinking is integrated into the "five levels and three categories" system of land and space planning and management, so as to realize the seamless connection between the three districts and three lines and the land and space planning and management.

\subsection{Clear development path}

The fundamental significance of "double evaluation" as a basic study of territorial spatial planning is to form a scientific understanding of the formation mechanism of the regional function itself, the characteristics of the evolution of the distribution pattern, and the law of spatial organization, and establish a long-term early warning mechanism for carrying capacity. Guide the green development, high-quality development and coordinated development of land and space. Through the process of comprehensive analysis and evaluation in the early stage, a comprehensive "physical examination" of resources and environmental endowments and spatial pattern characteristics and full control of relevant data are carried out. The main technical point is to identify the regional background conditions of water resources, land resources, climate resources, animal and plant resources, and environmental resources. Not only do we need to divide the space according to the advantages and disadvantages as the basis for spatial development methods, but also Provide reference for resource protection and utilization.

Table 5 Achievement Application Mechanism in Double Evaluation

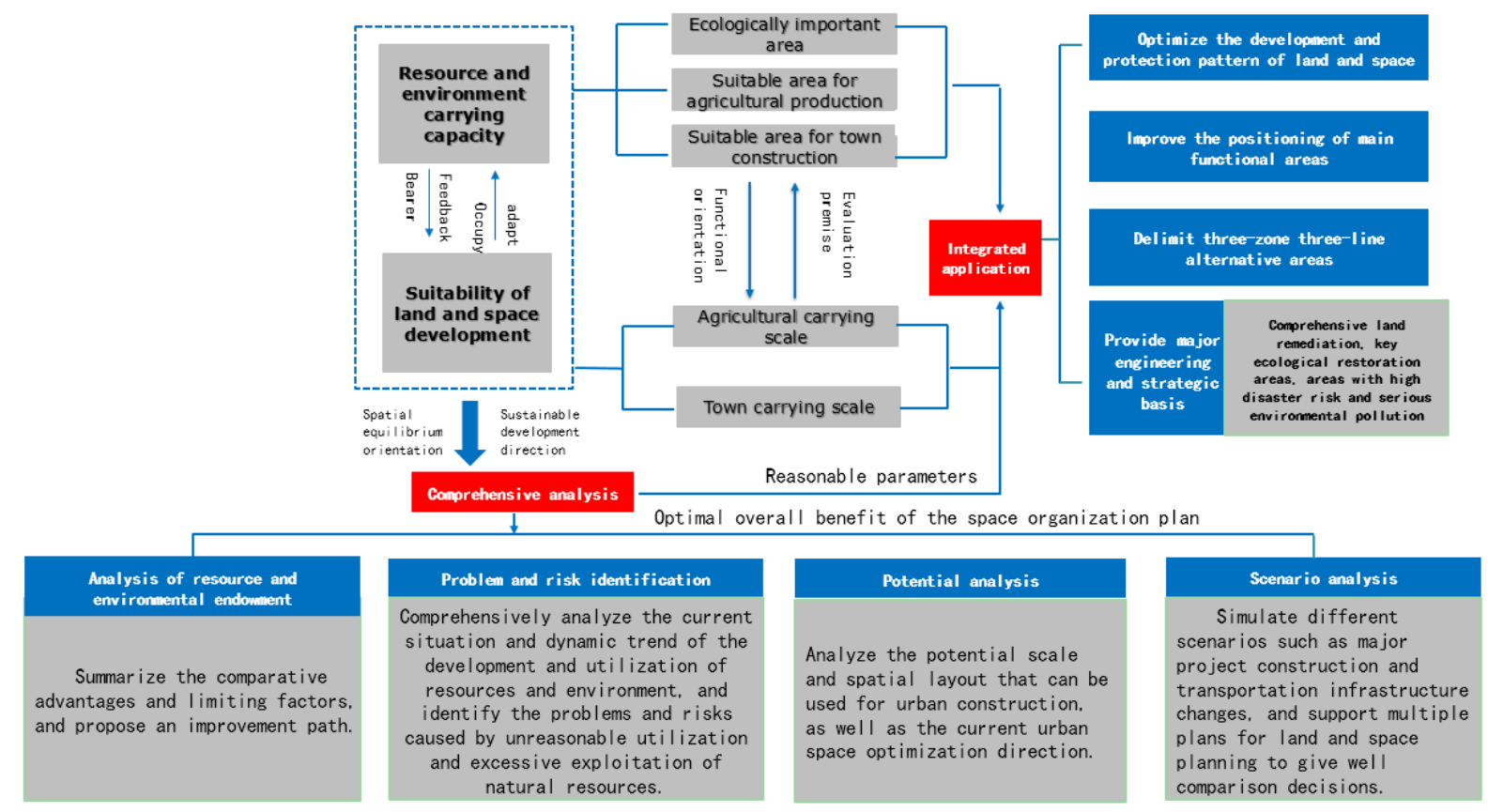

\section{4 summary}

Based on the depth of the municipal-level territorial and spatial master planning guidelines, the "double evaluation" is analyzed in relation to the functional orientation and main planning content. At the basic space level, the "double evaluation" clarifies the development direction by framing the scale and restricting the boundary, supporting the formulation of "strategic" content such as city-level planning goals and development positioning, and guiding the implementation of the next-level planning space strategy; At the level of structure and function, the "double evaluation" prejudges the three types of spatial layouts, clarifies the development area, connects the results of the main functional area of the municipal territorial space, and supports the delineation of provincial functional zoning and control lines; At the level of resource elements, "double evaluation" uses various resource evaluations to identify development paths, corresponding to the preparation of special plans for cultivated land protection, ecological restoration, transportation systems, cultural protection, and infrastructure construction in the city and county twolevel planning.

Therefore, the fundamental role of "double evaluation" in land and space planning runs through the entire planning process, and its essence is the spatial prediction of the way of land space development, protection and utilization, through basic space-pattern function-resource background. At the level, clarify the 
spatial development direction-development areadevelopment path, and provide support for scientific and reasonable planning.

\section{References}

1. Luo Qing, Fan Xinsheng, Gao Genghe et al. Spatial Distribution Characteristics and Influencing Factors of Poor Villages in Qinba Mountain Area[J]. Economic Geography 2016, 36(4): 127-132.

2. YuanY, WangYl, MaJet al. Multidimensional assessment of county poverty in Hebei Province[J].Progress in Geography Science 2014,33(1):124-133.

3. Wang Jinfeng,Xu Chengdong.Geographic Detector: Principles and Prospects[J].Journal of Geographical Sciences 2017,72(1):116-134.

4. HE Shen-jing,LIU Yu-ting,WU Bin-long.Poverty agglomeration, poverty characteristics and determinants of different social groups in Nanjing[J].Geographical Research,2010,29(4):704715 .

5. Kong Fanbin.Analysis of Rural Poverty Characteristics and Demand for Poverty Alleviation Funds in Binhu District of Poyang Lake Ecological Economic Zone[J].Economic Geography,2011,31(9):1545-1551.

6. Liu Ys,Li Jint.Geographic Detection and Optimization Decision-making ofDifferentiation Mechanisms of Rural Poverty in China[J].Acta GeographicaSinica,2017,72(1):161-173.

7. Liu Yanhua,Xu Yong.Geographic Identification and Type Division of Multi-Dimensional Poverty in Rural China[J].Journal of Geographical Sciences,2015,70(6):993-1007.

8. ZHAO Y,LIU Xp,GUO Yj.Analysis of Spatial Poverty Characteristics Model in Liupan Mountain Area of Ningxia Based on GIS[J].Research of Soil and Water Conservation,2014,21(5):95-99.

9. Luo Q,Li Xj.Progress in the Study of Rural Poverty Geography in Foreign Countries[J].Economic Geography,2014,34(6):1-8.

10. WangYh,QianLy,Duan Fuzhou.Study on MultiDimensional Poverty Measurement and Its Spatial Distribution Pattern at County Level__ Taking Key Poverty Counties in Detachment Areas as an Example[J].Geographical Science,2013,33(12):1491-1497.

11. Liu Xiaopeng,Su Shengliang,Wang Yajuan, et al.Study on the indicator system of spatial poverty measurement in villages with special difficulties in concentrated areas[J].Geographical Science, 2014,34(4):447-453.

12. TianY,XuJ,MaXf .Multidimensional Poverty Measurement and Its Spatial Representation in WulingMountain Area[J].Geographical Science,2017,37(1):162-169. 